\title{
Cross-modality matches between color and size differences
}

\author{
PASCHAL N. STRONG, JR. ${ }^{1}$ AMD ZITA TYER
}

TEXAS TECHNOLOGICAL COLLEGE

Eighteen undergraduates, 9 males and 9 females, were asked to make two geometric figures appear as different as two primary colors. They adjusted the size of one of the figures. There was a significant relation between the ratio of wave lengths of the colors and the ratios produced between the figures. Females tended to see a given color pair as more different than males.

Stevens (1957) divided perceptual continua into two categories, prothetic and metathetic. The former are quantitative sensory experiences while the latter are qualitative experiences. The prothetic continua follow a power function and, in a number of articles (Stevens, Mack \& Stevens, 1960; Stevens, 1959, 1966), it was demonstrated that derived power functions would predict the obtained results using a crossmodality matching technique.

Previous research by the senior author on oddity learning (Strong, 1963) revealed that monkeys, chimpanzees, and humans all found odddity based on size more difficult to learn than that based on form or color. The question arose as to whether or not this difference was due to size being a more difficult, less obvious dimension than color. It was also possible that the difference between colors used was subjectively greater than the size difference. A crude cross-modality matching experiment indicated that the size differences were about equal to the perceived color differences. The color stimuli, however, were the same used in the oddity learning and not matched for brightness and were not pure primaries.

The present experiment was undertaken to see if perceived differences between equally bright pairs of primary colors are related to their wavelength differences. Because pilot work suggested a possible sex differential, this variable was also included in the experiment.

\section{Subiects}

Eighteen Texas Technological College freshmen, nine males and nine females, were used. All had normal color vision and a postexperimental test indicated they had no knowledge about the wavelengths of color, their positions in the spectrum, or the relation of one color to another.

\section{Apparatus}

The apparatus consisted of a $30 \times 40$ in. frame containing a frosted glass screen placed upright on the floor. Thirteen feet behind the screen was a Kodak Carousel projector containing 63 slides of white stimulus objects on a black background. The stimulus objects were 21 pairs of circles, squares, or triangles. The standard stimulus was seen on the right and the variable stimulus on the left. The standard stimulus for all three figures had the same area, and the area of the adjustable stimuli varied in ratio to the standard from 1.0 to 0.1 . Two $15 \times 16$ in. boxes enclosing a light source and a polarimeter rested on the frame containing the screen. In the front of each box was a $3 \times 3$ in. opening before which gelatin filters could be placed. Four filters were used, red, green, blue, and yellow (Kodak Wratten filters A, B, C5, K2).

\section{Procedure}

Ss were brought into the testing room and seated $7 \mathrm{ft}$ from the apparatus. Each $\mathrm{S}$ was given a Farnsworth Dichotomous test for color blindness. Ss were then given an instruction sheet which read as follows: "You see before you a blank screen and two colored filters. Your task will be to tell me when the color on the right appears to be as bright as the one on the left."

The yellow filter was used as a standard and always placed on the left of S. E adjusted the polarimeter until $S$ reported the two colors equally bright. Each filter was paired with the yellow so that Ss made three equal brightness judgments. Ss' judgments were noted so that all pairs of colors would be equally bright. Ss were then given a second instruction sheet which read as follows: "You see before you two filters of different colors and two figures of different sizes. The figure on your left can vary in size until the two are equal. Your task will be to tell me how different those two colors seem to you. I am going to change the size of the figures and when the difference between those two figures is as great as the apparent difference between those two colors, tell me and I will stop. If we overshoot or undershoot the mark, tell me and I will back up."

Ss were randomly assigned to make judgments on one of the three figures. Each $S$ was given 18 trials consisting of six practice and 12 test trials. The practice trials consisted of three ascending and three descending trials with the colors paired in all possible combinations. The order of presentation of the ascending and descending trials was counterbalanced. Each pair of colors was presented 


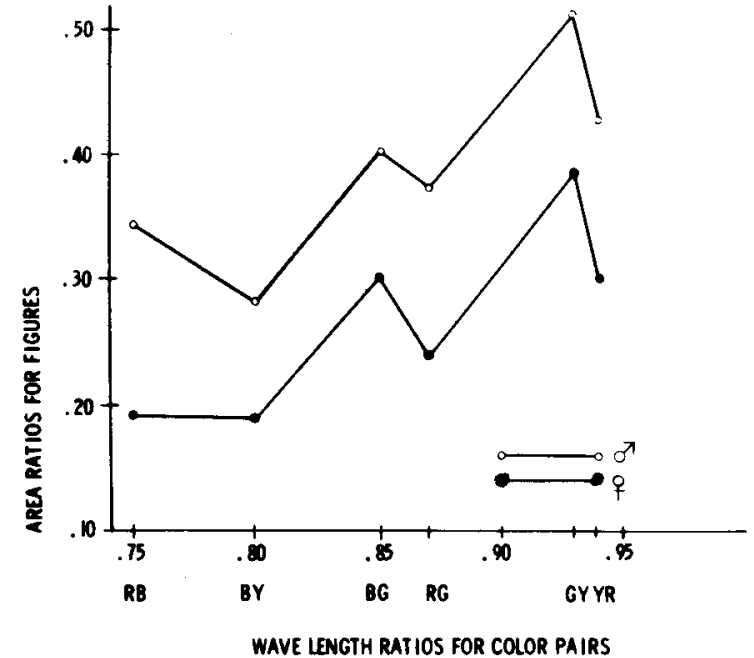

Fig. 1. Produced ratios of figure size as a function of color pair wave length ratios. 3

in random order and each was given twice to avoid a position bias. No time restriction was placed on Ss in making judgments. Upon completion of the test trials, Ss were given the questionnaire designed to determine his or her knowledge of color.

\section{RESULTS}

A preliminary analysis of variance indicated no significant differences between types of figures used, position of color, or ascending and descending trials. Consequently data for all figures was combined and a 2 by 6 analysis of variance (sex by color pairs) was calculated. The dependent variable was the ratio of the adjustable figure area to the standard.

Both main effects were significant (for sex, $F=$ 5.00, $\mathrm{df}=1 / 96$; for color pair, $\mathrm{F}=2.00, \mathrm{df}=5 / 96$ ) while the interaction was not significant. Figure 1 shows for each sex, the relation between ratio of wavelengths and ratio of figure areas produced in the cross-modality matches. Analysis of the orthogonal polynomials (Hayes, 1963) indicates that the linear trend $(F=14.72)$ and the quintic trend $(F=$ 6.76) are significant. 2

\section{DISCUSSION}

Figure 1 shows that as the ratio of the wavelengths of two primary colors increases so does the adjusted ratio of the figures. The remarkable parallelism of the two functions and the significant quintic trend for the combined data suggest that the deviations from a straight line are real. The cause may be a lateral induction effect, since the red-green pair and yellow-blue pair were seen as more different than would be expected. Since each could induce its complement into the other, their relative intensity or saturation would increase. The yellow-red pair, however, does not fit this hypothesis. It was our subjective opinion that the yellow K2 filter was not a pure yellow but had some green in it. This may have some bearing on the deviation of the yellow-red pair. Whatever it is due to, the phenomenon certainly deserves further investigation.

The question arises as to whether or not color is a prothetic or metathetic continuum. Indow and Stevens (1966) showed that changes in hue between two primaries follows a power function. However, primary colors are supposedly not seen as a mixture. The ability of Ss, naive as to wavelength and distribution of colors along the visible spectrum, to order primary pairs as a function of wavelength ratios suggests that they are responding quantitatively to the primary colors.

The data also indicate a significant sex effect in which females see a given color pair as more different than do males. This finding is in line with other studies indicating that girls can name colors faster than boys (Woodworth \& Wells, 1911; Ligon, 1932) and are more consistent in relating color names to color space (Chapanis, 1965). Seeing a given color pair as more different indicates that color discrimination is better for females than males.

\section{References}

Chapanis, A. Color names for color space. Amer. Sci., 1965, 53, 327-346.

Indow, T., \& Stevens, S. S. Scaling of saturation and hue. Percept. \& Psychophys., 1966, 1, 253-271.

Hays, W. L. Statistics for Psychologists. New York: Holt, Rinehart \& Winston, 1963. Pp. 551-558.

Ligon, E. M. A genetic study of color naming and word reading. Amer. J. Psychol., 1932, 44, 103-122.

Stevens, J. C., Mack, J. D., \& Stevens, S. S. Growth of sensation on seven continua as measured by force of handgrip. J. exp. Psychol., 1960, 59, 60-67.

Stevens, S. S. On the psychophysical law. Psychol. Rev., 1957, $64 ; 153-178$.

Stevens, S. S. Cross-modality validation of subjective scales for loudness, vibration and electric shock. J. exp. Psychol., 1959, 57, 201-208.

Stevens, S. S. Matching functions between loudness and ten other continua. Percept. \& Psychophys., 1966, 1, 5-9.

Strong, P. N. Studies in comparative psychophysiology. Final Report AF Contract \#29(600)-2939.

Woodworth, R. S., \& Wells, F. L. Association tests. Psychol. Monogr., 1911, 13, 1-85.

\section{Notes}

1. Now at the University of South Florida.

2. The use of this analysis is not fully justified by the data since the color pair ratios are not separated by equal intervals, a requirement for this analysis. However it is not felt by the authors that the deviations from this assumption is too extreme and thus it is used as a first approximation.

3. The ratios between figure-sizes and wave lengths were determined by dividing the larger figure into the smaller. Consequently, the smaller the ratio the larger the difference.

(Accepted for publication September 15, 1967.) 